\begin{abstract}
HHS Public Access
Author manuscript

J Econ Psychol. Author manuscript; available in PMC 2019 June 01.

Published in final edited form as:

J Econ Psychol. 2018 June ; 66: 13-21. doi:10.1016/j.joep.2018.03.005.

\section{Cigarette tax rates, behavioral disengagement, and quit ratios among daily smokers}

\author{
Rebecca Ferrer ${ }^{1}$, Edward Orehek ${ }^{2}$, Michael F. Scheier ${ }^{3}$, and Mary E. O'Connell ${ }^{4}$ \\ ${ }^{1}$ Basic Biobehavioral and Psychological Sciences Branch, Behavioral Research Program, \\ National Cancer Institute, Bethesda MD \\ 2University of Pittsburgh Department of Psychology, Pittsburgh PA \\ ${ }^{3}$ Carnegie Mellon University Department of Psychology, Pittsburgh PA \\ ${ }^{4}$ Behavioral Research Program, National Cancer Institute, Bethesda MD
}

\section{Abstract}

Cigarette taxation is an economics-based policy associated with increased population-level quit ratios. However, the estimated effects of tax increase on smoking behavior vary substantially, underscoring the need to identify moderating variables. We examined whether behavioral disengagement - the tendency to abandon goals when experiencing stress - modified the association between cigarette taxes and daily smoking behavior. We connected state-level cigarette tax rate data with individual-level behavioral data, including a national sample of 725 US adults who smoked daily at baseline and reported follow-up data approximately 10 years later, and 376 who were resampled a third time after another 10 years. Analyses involved multilevel logistic regression (with time as a nested variable and anonymized state codes as a grouping variable), where current smoking status (dichotomous) was regressed on behavioral disengagement, statelevel cigarette tax at baseline and current time, and the interaction between disengagement and current tax. Consistent with hypotheses, tax rate interacted with disengagement ( $O R=0.95,95 \%$ $C I=0.90,0.99, p=.0255)$ : Among those one $S D$ above the mean for disengagement, tax rate was unassociated with quit ratio ( $O R=0.99,95 \% C I=0.85,1.16, p=.6975)$. However, among those one $S D$ below the mean, tax rate was significantly associated with higher quit ratio $(O R=1.22,95 \%$ $C I=1.04,1.43, p=.0163)$. Our data suggest the possibility that cigarette taxes may be more effective in facilitating cessation among smokers low in behavioral disengagement or when accompanied by interventions that reduce stress or maintain goal pursuit. Identifying psychological moderators of policy effectiveness holds promise for improving policy design and targeting.
\end{abstract}

\title{
Keywords
}

taxes; stress and coping; goal disengagement; behavioral economics; smoking; public policy

Corresponding Author: Rebecca Ferrer, PhD, Basic Biobehavioral and Psychological Sciences Branch, Behavioral Research Program, National Cancer Institute, 9609 Medical Center Dr., Bethesda, MD 20892, Phone: (240) 276-6914, ferrerra@ mail.nih.gov.

Publisher's Disclaimer: This is a PDF file of an unedited manuscript that has been accepted for publication. As a service to our customers we are providing this early version of the manuscript. The manuscript will undergo copyediting, typesetting, and review of the resulting proof before it is published in its final citable form. Please note that during the production process errors may be discovered which could affect the content, and all legal disclaimers that apply to the journal pertain. 


\section{Introduction}

\subsection{Cigarette taxation}

Cigarette taxes are a relatively effective, economics-based population-level tobacco control strategy (Chaloupka, Yurekli, \& Fong, 2012; Contreary et al., 2015; DeCicc \& McLeod, 2008; Flewelling et al., 1992; Jha \& Peto, 2014; Peterson et al., 1992). Because cigarette smoking is the leading behavioral cause of premature death in developed countries (Jha, 2009), such effective tobacco control strategies are important tools to encourage cessation. Accordingly, taxes are a key component of many tobacco control recommendations (Fong et al., 2006; Levy et al., 2016; TFCS, 2001). However, estimates of the association between tax rates and smoking vary substantially (CDC, 2015; Contreary et al., 2015; Ranson et al., 2002; Tauras et al., 2001). Although in general decline, the U.S. smoking rate remains high at $16.8 \%$, with certain sub-populations smoking at even higher rates (CDC, 2015). Cigarette demand declines are capped ( 7-15\%) even in simulations that incorporate high (20\%) tax rates (Contreary et al., 2015), suggesting not all smokers respond as expected to tax increases. Thus, it is critical to identify individual characteristics with the potential to moderate the effectiveness of economics-based strategies such as taxation, an approach that is analogous to the microsegmentation approach cigarette companies have used to target distinct consumer groups based on psychological factors (Greenland, 2013; Ling \& Glanz, 2002).

Although sociodemographic moderators of cigarette tax effectiveness, such as income and education, have been examined (Coady et al., 2013; Flewelling et al., 1992; Townsend et al., 1994), these are difficult or impossible to intervene upon. Conversely, select psychological moderators may be modifiable (Coady et al., 2013; Ferrer et al., 2015; Fong et al., 2006). A deeper understanding of psychological moderators that affect health behaviors can yield hypotheses that inform prospective, longitudinal investigation and ultimately lead to the development of complementary interventions to augment or optimize tax effectiveness. Prominent frameworks posit that tobacco policies trigger behavioral processes moderated by psychological factors (Fong et al., 2006). Moreover, evidence suggests psychological factors (e.g., stress) may modify the effectiveness of other types of tobacco control policies (e.g., smoke-free laws) (Meijer et al., 2015; Persoskie et al., 2015; Rennen et al., 2014). However, little research has examined psychological factors with the potential to modify responses to cigarette taxes.

Taxes are more strongly associated with quit attempts than sustained cessation (Bush et al., 2012), perhaps because motivation to quit predicts whether people will attempt cessation but not whether they will remain quit (Borland et al., 2010). One individual characteristic that may moderate the effectiveness of cigarette taxes for sustained cessation is behavioral disengagement from goals under stress. Behavioral disengagement is the tendency to abandon attempts to attain goals with which a stressor interferes (Carver, Scheier, \& Weintraub, 1989). Although cigarette taxes may cause people to want to quit smoking increase the salience of existing motivation to quit smoking - individuals high in behavioral disengagement may abandon the goal when cessation becomes difficult and/or stressful. 


\subsection{Behavioral disengagement from goals under stress}

People differ from one another in how they manage goal pursuit when they are experiencing stress, or when goal pursuit is itself stressful. For example, some individuals try to reinterpret stressful situations or vent their emotions to down-regulate the experience of stress, while others cope by taking direct action to solve the stressful problem, and still others try to deny that the stressful situation is occurring (Carver et al., 1989).

One common strategy, particularly when goal pursuit is inherently stressful or when goals seem unattainable given other stressful circumstances, is to behaviorally disengage from the goal - that is, to reduce efforts or attempts to achieve the goal (Carver et al., 1989).

Disengagement is likely to occur when goal pursuit is difficult and expectations for success are low, because stress cues individuals to disengage from goals perceived as unattainable (Carver \& Scheier, 1990). Behavioral disengagement from goals can be beneficial if it freesup resources to pursue alternative goals an individual is more committed to or likely to attain (Wrosch, Scheier, Carver, \& Schulz, 2003a; Wrosch, Scheier, Miller, Schulz, \& Carver, 2003b; Wrosch, Scheier, \& Miller, 2013). Disengagement from goals can also be beneficial for mental well-being (Carver \& Scheier, 1990; Wrosch et al., 2003a, 2003b, 2013). However, disengagement from important goals such as those related to health can be harmful. Moreover, behavioral disengagement may result in maladaptive behavioral decisions when it disrupts progress towards goals an individual is highly motivated to achieve.

Behavioral disengagement is a particularly important coping strategy to examine in the context of smoking, which is highly addictive and thus difficult to quit (Benowitz, 2010), with high rates of cessation failure (Hughs et al., 2004). Indeed, abstinence is characterized by withdrawal and cravings (Loewenstein, 1999), and so smoking cessation is itself stressful (Cohen \& Lichtenstein, 1990; Shiffman et al., 1996). Moreover, smokers often view smoking as a means of coping with stress arising from other situations (e.g., work-related stress) (Kassel et al., 2003; Niaura et al., 2002; Saladin et al., 2012; Shiffman, 1993), particularly when other emotion regulatory techniques have failed (Fucito, Juliano, \& Toll, 2010; Mager, Phillips, \& Hosie, 2008), and those who smoke to reduce stress are less likely to quit successfully (Conklin \& Perkins, 2005).

Tendency towards behavioral disengagement under stress may thus play an important role in the cessation process, and may disrupt pathways through which cigarette taxes could ordinarily activate goals and lead to successful cessation. For example, it is possible that cigarette taxes could lead individuals to contemplate or plan to quit, but that tendency towards behavioral disengagement could prevent those plans from translating into action (i.e., an actual quit attempt) (see Gökbayrak, 2015; Velicer et al., 1998, for discussions of stress, movement from contemplation to planning to action, and relapse). Further, even if individuals actually take steps to quit smoking in response to cigarette taxes, people high in behavioral disengagement may not persist in those actions. Note that individuals are not always aware of their goals and motives (Kruglanski et al., 2002, 2013), and as such it is possible that behavioral disengagement may interfere with the motivational properties of cigarette taxes even if individuals are unaware of a potential cessation goal or do not take explicit steps to reach that goal. 


\subsection{The present study}

Despite its important theoretical role in smoking cessation, behavioral disengagement has not been studied as a barrier to cessation or as a moderator of the effects of tobacco control strategies. The present study is an initial attempt to fill this gap by matching individual-level psychological and behavioral data from a national U.S. health study with state-level data on cigarette tax rates. The goal was to examine the hypothesis that behavioral disengagement would moderate the association between tax rates and quit ratios (i.e., the rate of smoking cessation among those who smoked at a previous time point). We predicted behavioral disengagement would be associated with lower likelihood of cessation; higher tax rates would be associated with increased likelihood of cessation; and tax rates would be more strongly associated with cessation among those low in behavioral disengagement. We focused on cessation of daily smoking consistent with the operationalization of smoking status in these data. We also argue that behavioral disengagement may be most likely to interfere with cessation goals among individuals who have the strongest challenge to overcome (i.e., people who smoke regularly and may thus tend to be more nicotinedependent; Kassel et al., 1994).

We also conducted analyses to investigate alternative explanations for any observed interaction between taxation and behavioral disengagement. First, we conducted analyses involving the interaction of tax rates and other psychological variables that may be conceptually related to goal pursuit or behavioral disengagement, including neuroticism, conscientiousness, optimism. These variables have been associated with behavioral disengagement in past work, and may serve as important predictors of coping styles (including behavioral disengagement) because they help to generate the expectancies through which coping styles are selected (e.g., Scheier \& Carver, 1992; Scheier, Carver, \& Bridges, 1994). For example, individuals who are optimistic in nature may perceive success on goal achievement to be more likely, and thus be less likely to behaviorally disengage, whereas those who are higher in neuroticism may perceive success as less likely and disengage more frequently. We also examined other common responses to difficult to achieve goals, including general goal adjustment and focus on goal achievement, to examine whether other coping styles might exhibit a similar pattern of moderation (or may explain any moderating effects of behavioral disengagement).

We also examined whether behavioral disengagement interacted with smoke-free air law in predicting cessation. Smoke-free air laws, which restrict smoking in areas such as workplaces and restaurants, are intended to protect non-smokers from second-hand smoke (Callinan et al., 2010, U.S. Department of Health and Human Services, 2006), but may also encourage quit attempts and cessation among smokers (Fowkes et al., 2008; Hackshaw et al., 2010; Nagelhout et al., 2012), and have been shown to interact with psychological factors in predicting intentions to quit (Persoskie et al., 2015). 


\section{Material and Methods}

\subsection{Participants and procedures}

Data were drawn from the MidLife in the US (MIDUS) 1 (M1; 1995-1996), 2 (M2; 20042006), and 3 (M3; 2013) surveys, which included a longitudinal national U.S. sample of adults aged 24-75 (at M1). Additional details about the study (including a complete list of measures) is at http://www.midus.wisc.edu.

Individuals who reported smoking at least a few cigarettes daily at M1 or M2 were included in the study. The final sample included 725 participants (55.86\% female) who smoked cigarettes regularly (at least a few every day) at M1 (and had data for all relevant variables), and of those, 336 reported smoking cigarettes daily at M2 (and had data for all relevant variables) and thus had a second line of data included in analyses. Descriptive statistics for participants at M2 and M3 (i.e., those included as control variables in analyses) are found in Table 1.

\subsection{Measures}

At M1, M2, and M3, smoking status was assessed with a single item: Do you smoke cigarettes regularly NOW?" (yes/no) (the previous item in the survey asked whether they had ever smoked regularly, defining 'regularly' as at least a few cigarettes each day). For Time 1, the M1 smoking variable was used to exclude individuals who did not smoke regularly at baseline, and the M2 smoking variable was used as the outcome (quit ratio). For Time 2, the M2 smoking variable was used to exclude individuals who did not smoke regularly at $\mathrm{T} 2$, and the $\mathrm{M} 3$ smoking variable was used as the outcome (quit ratio).

Cigarette tax rates at the beginning of 1996, 2004, and 2013 (to match year, as closely as possible, to data collection dates from MIDUS for M1, M2, and M3, respectively) were coded at the state-level from the American Lung Association (ALA) database (1996, 2004, 2013; http://www.lungusa2.org/slati/tobacco_taxes.php) and matched with MIDUS data (M1: 1996; M2: 2004; M3: 2013) using Federal Information Processing Standard (FIPS) state codes by MIDUS staff. The dataset does not include a state variable for each individual, but rather a FIPS "nonsense code," which protects personally-identifiable information with a unique code assigned to each state, rather than address, in accordance with MIDUS confidentiality procedures.

Smoke-free air policies were extracted from the ALA State of Tobacco Reports in 2004 and 2013. These reports indicated whether each state had smoke-free policies in government worksites, private worksites, schools, childcare facilities, restaurants, bars, retail stores, and recreation/ cultural facilities. Each category was scored dichotomously $(1=$ state policy in place; $0=$ no state policy in place), and then the eight category scores were summed to create a total score (ranging from $0=$ no policies in place to $8=$ all policies in place). The year 1996 predates ALA State of Tobacco Reports, and as such, smoke-free policies were connected only to M2 and M3.

Behavioral disengagement was assessed with four items (Carver et al., 1989), all beginning with the same stem: "Please circle the number that best described how you usually 
experience a stressful event:": 1) I give up trying to reach my goal," "I admit to myself that I can't deal with it, and quit trying," "I give up the attempt to get what I want," and "I reduce the amount of effort I'm putting into solving the problem." Answer options were $1=\mathrm{a}$ lot through $4=$ not at all, and items were reverse-scored and then averaged. Scale reliability was acceptable (M2: $a=.73 ; \mathrm{M} 3: a=.74)$. Note that behavioral disengagement was not assessed at M1.

General goal adjustment and focus on goal achievement (Wrosch et al., 2000) were assessed with a series of items. Items associated with general goal adjustment included: "When my expectations are not being met, I lower my expectations;" "To avoid disappointments, I don't set my goals too high;" and "I feel relieved when I let go of some of my responsibilities." Items associated with focus on goal achievement included: "When things don't go according to my plans, my motto is: "Where there's a will, there's a way;" "When faced with a bad situation, I do what I can to change it for the better;" "Even when I feel I have too much to do, I find a way to get it all done;" "When I encounter problems, I don't give up until I solve them;" and "I rarely give up on something I am doing, even when things get tough." These items were all on a four-point scale, and were averaged within each scale.

Conscientiousness and neuroticism were assessed with items from the Big 5 (John, 1990). The item stem was: "Please indicate how well each of the following describes you?" (a 4point response scale was used). Conscientiousness adjectives included: organized, responsible, hardworking, and careless (reverse-scored). Neuroticism items included: moody, worrying, nervous, and calm (reverse-scored). Optimism was assessed with items from the Life Orientation Test-Revised (Scheier, Carver, \& Bridges, 1994), on 4-point scales. Items included: "In uncertain times, I usually expect the best;" "I'm always optimistic about my future;" and "I expect more good things to happen to me than bad." Self-reported health was assessed with a single item: "In general, would you say your physical health is excellent, very good, good, fair, or poor?"

\subsection{Analyses}

Analyses were conducted in SAS 9.3, using the glimmix procedure, with FIPS nonsense code used as a grouping variable and Time (two levels, M1 to M2 and M2 to M3) nested within subject, and restricted only to individuals who reported smoking at baseline (M1 or M2, depending on Time). Time did not interact with any study variable, and as such no interactions including time were included in the final model. The final model regressed smoking status (current regular smoking: yes or no) on tax rates at follow-up (M2 or M3, depending on Time) controlling for tax rates at baseline (M1 or M2, depending on Time), behavioral disengagement, and the interaction of tax rates at follow-up and behavioral disengagement. Behavioral disengagement at baseline was not included in analyses because it was not assessed in M1.

Ancillary analyses were conducted using the same procedures described above, but probing the main associations of general goal adjustment, focus on goal achievement, optimism, conscientiousness, and neuroticism with quit ratios, as well as the interaction of these and tax rates in predicting quit ratios. Additional ancillary analyses were conducted to examine whether smoke-free policies have main associations with, or interact with behavioral 
disengagement in predicting, quit ratios. Because the ALA State of Tobacco reports do not date back to 1996, these analyses were restricted to Time 2 comparisons (M2 to M3), but otherwise followed the same procedures for main analyses described above (without Time as a nested variable).

Predictors were centered prior to creating interaction terms. Analyses controlled for age, gender, race (three levels, coded white, black, or other), and education (no high school diploma, high school diploma or some college, or college diploma; consistent with previous research capturing socioeconomic disadvantage by educational benchmarks that effectively delineate earnings; Almeida et al., 2005), all assessed at the same time as behavioral disengagement (at follow-up, M2 or M3 depending on Time). Analyses also controlled for self-reported health (assessed at the same time-point as sociodemographic control variables), because self-reported health is a strong predictor of physical health and mortality, independent of conventional risk factors (Idler \& Benyamini, 1997), and as such may be important to consider in the context of smoking cessation. Simple slopes analyses followed standard procedures (Aiken et al., 1991).

\section{Results}

\subsection{Main analyses}

Descriptive statistics for behavioral disengagement and tax rates at baseline and follow-up are found in Table 1. The total quit ratio was $66.4 \%$ at M2 and $42.9 \%$ at M3 (compared to the national average of $59.1 \%$ in 2015; Babb et al., 2017). The correlation between behavioral disengagement and tax rates was $r=0.01(p=.793)$ at M2 and $r=0.04(p=.447)$ at M3.

Results for the primary multilevel model appear in Table 2. Higher tax rates at T2, controlling for T1, were not significantly associated with quit ratio, although the association was in the expected direction $(O R=1.10,95 \% C I=0.97,1.26, p=.142)$. Behavioral disengagement was also not significantly associated with quitting, but again with an association in the expected direction ( $O R=0.94,95 \% C l=0.88,1.01, p=.094)$. Consistent with hypotheses, there was a significant interaction between tax rate and disengagement ( $O R=0.95,95 \% C I=0.90,0.99, p=.026$; Figure 1). Among those one $S D$ above the mean for disengagement, tax rate was unassociated with quitting $(O R=0.99,95 \% C I=0.85,1.16, p=$. 698). However, among those one $S D$ below the mean, tax rate was significantly associated with quitting ( $O R=1.22,95 \% C l=1.04,1.43, p=.016)$.

\subsection{Analyses of alternative psychological predictors and moderators}

Optimism was associated with higher quit ratio $(O R=1.09,95 \% C I=1.03,1.15, p=.002) .{ }^{1} \mathrm{In}$ contrast, the main effects of the following variables on quit ratio were not significant: focus on goal achievement $(O R=1.12,95 \% C I=0.89,1.42, p=.340)$, general goal adjustment ( $O R=0.86,95 \% C I=0.67,1.10, p=.224)$, neuroticism ( $O R=0.83,95 \% C I=0.67,1.02, p=.074)$, or conscientiousness $(O R=1.31,95 \% C I=0.99,1.74, p=.062)$. None of the above

\footnotetext{
${ }^{1}$ Note that including optimism as a control variable in the main analyses did not change the pattern or significance of the interaction between tax rate and disengagement on quit ration, $O R=0.95,95 \% C I=0.90,0.99, p=.022$
} 
psychological predictors interacted with tax rate: optimism ( $O R=0.97,95 \% C I=0.94,1.02$, $p=.120)$, focus on goal achievement $(O R=1.07,95 \% C I=0.90,1.27, p=.437)$, general goal adjustment ( $O R=1.12,95 \% C I=0.92,1.71, p=.212)$, neuroticism $(O R=0.91,95 \%$ $C I=0.78,1.05, p=.190)$, or conscientiousness $(O R=1.02,95 \% C I=0.83,1.26, p=.846)$.

\subsection{Alternative explanations}

Ancillary analyses indicated no main association between smoke-free air policies and quit ratio $(O R=0.94,95 \% C I=0.79,1.13, p=.522)$, controlling for baseline smoke-free air policies ( $O R=1.11,95 \% C I=0.92,1.34, p=.284)$, nor did smoke-free air policies interact with behavioral disengagement $(O R=0.93,95 \% C I=0.63,1.38, p=.711)$.

\section{Discussion}

These findings are consistent with the hypothesis that behavioral disengagement may moderate the effectiveness of cigarette taxes for facilitating cessation. There was a significant association between tax rates and cessation among individuals low in behavioral disengagement. However, as expected, the association between tax rates and quit ratios was attenuated among those higher in behavioral disengagement. Importantly, we did not uncover unintended negative consequences (Balbach \& Campbell, 2009) such as, lower quit ratios, even among those higher in behavioral disengagement. Thus, cigarette taxes may be not only a means for discouraging initiation among youth (Callison \& Kaestner, 2014; Contreary et al., 2015; Ohsfeldt et al., 1998), but also a cost-effective means for facilitating cessation among established smokers, especially for those lower in behavioral disengagement (or when paired with interventions that discourage or mitigate disengagement).

Of note, tax rates did not interact with any other psychological variables related to behavioral disengagement (optimism, neuroticism, conscientiousness), or used in place of behavioral disengagement for coping with difficulties in goal achievement (goal adjustment, focus on goal achievement), in predicting quit ratios. Moreover, we observed no main effect of smoke-free laws on quit ratio and no interaction between smoke-free laws and behavioral disengagement. We can only speculate about potential reasons for the lack of observed effects, as prior studies have found smoke-free laws, like cigarette taxes, to motivate cessation (Fowkes et al., 2008; Hackshaw et al., 2010; Nagelhout et al., 2012). It is worth noting that our measure of smoking status focused on daily smoking, and it is conceivable that smoke-free laws could have their largest effects on the behavior of less frequent smokers, such as those who only smoke socially. Along similar lines, we focused on cessation rates of current smokers and did not test laws' potential effects on new initiation. Limited statistical power may also have played a role: Because ALA reports containing smoke-free grades were not available for M1, analyses of smoke-free laws were conducted only with the M2-M3 comparison. Future research should examine whether the motivational properties and psychological effects of smoke-free laws may differ from those of cigarette taxes. Unlike taxes, smoke-free laws are not expressly designed to motivate cessation, but rather to protect non-smokers from secondhand smoke (Callinan et al., 2010, U.S.

Department of Health and Human Services, 2006), which may play a role in how smokers

J Econ Psychol. Author manuscript; available in PMC 2019 June 01. 
perceive and respond to the laws. It is also possible that taxes are particularly stressful for smokers because they affect everyone who purchases cigarettes, whereas smoke-free laws generally do not restrict smoking in one's own home.

A main association between cigarette tax rate and smoking cessation rates did not emerge in these data, in contrast to previous findings and recommendations regarding cigarette tax rates (Chaloupka, Yurekli, \& Fong, 2012; Contreary et al., 2015; DeCicc \& McLeod, 2008; Flewelling et al., 1992; Jha \& Peto, 2014; Peterson et al., 1992). The final sample in our analyses was relatively small, in comparison to previous studies, and it is possible that these analyses were underpowered to detect a main effect. Indeed, prior research suggests the effect of tobacco taxes on the reduction of adult smoking is generally small (e.g., Callison \& Kaestner, 2014), and simulations suggest that taxation may be more effective at preventing initiation than promoting cessation (Contreary et al., 2015). As such, a larger sample may have uncovered a main effect, and a lack of a main effect in these analyses should be interpreted with caution. Future research should attempt to replicate these analyses in a larger sample.

Further research on the mechanisms underlying the effects of behavioral disengagement in this study would be useful for informing intervention strategies. People higher in behavioral disengagement may be more likely to experience cessation as difficult or stressful because they do not expect to succeed (Carver et al., 1989) or because they are motivated to fulfill craving and avoid nicotine withdrawal (Loewenstein, 1999). Alternatively, those low in behavioral disengagement may effectively manage stress through other means (Beckes \& Coan, 2011; Gross, 2013; Hall et al., 2002) or may be more comfortable experiencing stress (Tamir, 2009), negating the need to rely on smoking for stress reduction. Multiple explanations underscore the need for laboratory interrogations of mechanisms, and for including assessments of potential mechanisms (e.g., cessation difficulty, use of smoking as a stress reduction strategy) in future prospective, longitudinal studies of behavioral disengagement and cigarette taxes.

Nonetheless, the findings generate important hypotheses about ways to augment cigarette tax effectiveness by intervening on behavioral disengagement. Many current cessation interventions target risk perceptions, social norms, or self-efficacy (Aveyard et al., 2012; Durkin et al., 2012; Whittaker et al., 2012), or involve medication (Raupach et al., 2014). Some smokers (i.e., those high in behavioral disengagement) may prioritize stress reduction over cessation goals (Kopetz \& Orehek, 2015; Kruglanski \& Orehek, 2009) or adaptively abandon goals they perceive to be unattainable (Carver et al., 1989). For those higher in behavioral disengagement, medication or interventions targeting risk perceptions, social norms, or self-efficacy alone may be inadequate in absence of interventions for coping with stress or discouraging disengagement even when goal pursuit is stressful.

One promising approach for augmenting tax effectiveness may involve bolstering stress management resources to lessen reliance on smoking as a compensatory regulatory strategy (Ferrer, Green, \& Barrett, 2015). Another intervention that may combat disengagement involves facilitating implementation intentions (i.e., "if... then" plans that anticipate obstacles and identify strategies to overcome them) (Gollwitzer \& Sheeran, 2006), which 
can be incorporated into policies designed to facilitate smoking cessation (Rothman et al., 2015). Finally, tax effectiveness may be augmented by presenting environmental cues related to cessation goals (Papies \& Barsalou, 2015), which may facilitate goal activation and increase the likelihood of goal pursuit.

\subsection{Limitations and further research}

Although analyses leveraged longitudinal data across two time comparisons (M1-M2 and M2-M3) and a span of 20 years, there are several limitations with the data structure that warrant mention. First, we retrospectively matched taxes, behavioral disengagement, and taxes in an existing dataset. As such, the timing of assessments was not as ideal as it would have been in a prospectively developed study. For example, behavioral disengagement was assessed only at M2 and M3; this, in addition to the small number of individuals who smoked regularly at M2 and provided follow-up data at M3 (which did not provide statistical power for stand-alone analyses in this time comparison only) precluded accounting for behavioral disengagement at baseline in analyses. Even if behavioral disengagement had been assessed at M1, it would not be possible to match behavioral disengagement with when taxes increased, which varied substantially between states and often occurred multiple times within each 9-year assessment period. Moreover, behavioral disengagement at baseline would not necessarily (nor even usually) match with the time period in which quit occurred - on average, about halfway through each time comparison, but with substantial variability between individuals - nor would it be possible to determine whether behavioral disengagement at baseline or follow-up was most relevant in disrupting any motivational properties of cigarette taxes among those who did not quit. Therefore, future research should include more frequent assessments of behavioral disengagement, ideally matched to changes in state cigarette taxes and quit attempts in response to these changes.

Another limitation is a lack of data concerning the number of times individuals quit smoking, or whether they were actually motivated to quit by taxes (although note that individuals are often unable to report accurately on goals and motivations, meaning this information may only incompletely describe cessation motivations; Kruglanski et al., 2002; 2013). Other psychological variables unexamined in the present data, such as habitual use of emotion regulatory strategies or instrumental support for smoking cessation, may also moderate the association of taxation and cessation. Future research should examine a wider range of moderators and outcomes, including quit attempts, quit fatigue, motivation to quit smoking, and other potential psychological moderators, assessed at more frequent intervals. Future studies should also control for nicotine dependence and use of medication, as well as individual-level factors associated with smoking such as children and family information and contact with other smokers. These were not assessed here.

Study conclusions are limited to daily smokers, a population for whom disengagement may be especially salient given the difficulty and stressfulness of overcoming a high level of nicotine dependence. Future research is necessary to examine behavioral disengagement and tax rates among other populations, including those who smoke less regularly than daily. Similarly, it is critical to identify factors that may moderate the effectiveness of taxes for discouraging initiation, which we did not examine here, particularly among adolescent and 
young adult smokers. Analyses were also limited by reliance on self-reported smoking status as an outcome, although outside of some special populations (i.e., pregnant women, underage youth), self-reporting of smoking does not seem to be biased by social desirability (Persoskie \& Nelson, 2013). Finally, there was a lack of ethnic diversity in the sample.

These limitations are offset by a number of strengths, including the use of a longitudinal, national U.S. sample, the novelty of coupling population-level tax data with individual-level psychological and behavioral data, and a psychometrically sound, well-used measure of behavioral disengagement.

\section{Conclusions}

This is one of few studies in a nascent area of inquiry identifying individual characteristics that shape responses to population-level public health strategies, including those that are economics-based (Meijer et al., 2015; Persoskie et al., 2015; Rennen et al., 2014). The advantages of microsegmenting tobacco consumer groups are well understood by tobacco companies, but have not been fully utilized in tobacco control efforts and, even then, not in terms of the effects of broad policies such as taxes (Greenland, 2013; Ling \& Glanz, 2002). Findings are consistent with the hypothesis that cigarette taxes may be most effective for facilitating cessation when accompanied by supplementary interventions to deter goal disengagement. These findings also raise the possibility that goal disengagement could play a role in the success of other economics-based strategies that encourage stressful or difficult behavioral changes.

\section{Acknowledgments}

The MIDUS 2 research was supported by a grant from the National Institute on Aging (P01-AG020166) to conduct a longitudinal follow-up of the MIDUS 1 investigation. There is no additional funding to report. The authors have no conflicts of interest to report.

We thank Alexander Persoskie for his feedback on earlier versions of this manuscript.

\section{References}

Aiken LS, West SG, Reno RR. Multiple regression: Testing and interpreting interactions. Sage; 1991.

Almeida DM, Neupert SD, Banks SR, Serido J. Do daily stress processes account for socioeconomic health disparities? Journal of Gerontology Series B: Psychological Sciences and Social Sciences. 2005; 60:S34-S39.

American Lung Association (ALA). State of Tobacco Control: 2004. 2004.

Aveyard P, Begh R, Parsons A, West R. Brief opportunistic smoking cessation interventions: a systematic review and meta-analysis to compare advice to quit and offer of assistance. Addiction. 2012; 107:1066-1073. [PubMed: 22175545]

Babb S, Malarcher A, Schauer G, Asman K, Jamal A. Quitting Smoking Among Adults-United States, 2000-2015. MMWR Morbidity and mortality weekly report. 2017; 65

Balbach ED, Campbell RB. Union women, the tobacco industry, and excise taxes: a lesson in unintended consequences. American Journal of Preventive Medicine. 2009; 37:S121-S125. [PubMed: 19591750]

Beckes L, Coan JA. Social baseline theory: The role of social proximity in emotion and economy of action. Social Personality Psychology Compass. 2011; 5:976-988.

Benowitz NL. Nicotine addiction. NEJM. 2010; 362:2295. [PubMed: 20554984] 
Borland R, Yong HH, Balmford J, Cooper J, Cummings KM, O’Connor RJ, ... Fong GT. Motivational factors predict quit attempts but not maintenance of smoking cessation: Findings from the International Tobacco Control Four country project. Nicotine \& Tobacco Research. 2010; 12:S4S11. [PubMed: 20889479]

Bush T, Zbikowski S, Mahoney L, Deprey M, Mowery PD, Magnusson B. The 2009 US federal cigarette tax increase and quitline utilization in 16 states. Journal Environmental and Public Health. 2012

Callison K, Kaestner R. Do higher tobacco taxes reduce adult smoking? New evidence of the effect of recent cigarette tax increases on adult smoking. Economic Inquiry. 2014; 52:155-172.

Carver CS, Scheier MF. Origins and functions of positive and negative affect: A control-process view. Psychological Review. 1990; 97:19.

Carver CS, Scheier MF, Weintraub JK. Assessing coping strategies: a theoretically based approach. Journal Personality and Social Psychology. 1989; 56:267.

Centers for Disease Control and Prevention. Current Cigarette Smoking Among Adults-United States 2005 -2014. Morbidity and Mortality Weekly Report. 2015; 64:1233-1240. [PubMed: 26562061]

Chaloupka FJ, Yurekli A, Fong GT. Tobacco taxes as a tobacco control strategy. Tobacco Control. 2012; 21(2):172-180. [PubMed: 22345242]

Coady MH, Chan CA, Sacks R, Mbamalu IG, Kansagra SM. The impact of cigarette excise tax increases on purchasing behaviors among New York city smokers. American Journal Pub health. 2013; 103:e54-e60.

Cohen S, Lichtenstein E. Perceived stress, quitting smoking, and smoking relapse. Health Psychology. 1990; 9:466. [PubMed: 2373070]

Conklin CA, Perkins KA. Subjective and reinforcing effects of smoking during negative mood induction. Journal of Abnormal Psychology. 2005; 114:153. [PubMed: 15709822]

Contreary KA, Chattopadhyay SK, Hopkins DP, Chaloupka FJ, Forster JL, et al. Economic impact of tobacco price increases through taxation: a Community Guide systematic review. American Journal of Preventive Medicine. 2015; 49:800-808. [PubMed: 26188686]

DeCicc P, McLeod L. Cigarette taxes and older adult smoking: evidence from recent large tax increases. Journal of Health Economics. 2008; 27(4):918-929. [PubMed: 18178277]

Durkin S, Brennan E, Wakefield M. Mass media campaigns to promote smoking cessation among adults: an integrative review. Tobacco Control. 2012; 21:127-138. [PubMed: 22345235]

Ferrer RA, Green PA, Barrett LF. Affective Science Perspectives on Cancer Control Strategically Crafting a Mutually Beneficial Research Agenda. Perspectives on Psychological Science. 2015; 10:328-345. [PubMed: 25987511]

Ferrer RA, Klein WMP, Lerner JS, Reyna V, Keltner D. Emotions and health decision making: Extending the Appraisal Tendency Framework to improve health and health care. In: Roberto C, Kawachi I, editorsBehavioral Economics and Public Health. New York, NY: Oxford University Press; 2015.

Flewelling RL, Kenney E, Elder JP, Pierce J, Johnson M, Bal DG. First-year impact of the 1989 California cigarette tax increase on cigarette consumption. American Journal of Public Health. 1992; 82(6):867-869. [PubMed: 1585966]

Fong GT, Cummings KM, Borland R, Hastings G, Hyland A, Giovino GA, Thompson ME. The conceptual framework of the International Tobacco Control (ITC) policy evaluation project. Tobacco Control. 2006; 15:iii3-iii11. [PubMed: 16754944]

Glanz K, Bishop DB. The role of behavioral science theory in development and implementation of public health interventions. Annual Review of Public Health. 2010; 31:399-418.

Gollwitzer PM, Sheeran P. Implementation intentions and goal achievement: A meta-analysis of effects and processes. Advances in Experimental Social Psychology. 2006; 38:69-119.

Greenland SJ. Cigarette brand variant portfolio strategy and the use of colour in a darkening market. Tobacco Control. 2013

Gross JJ. Emotion regulation: taking stock and moving forward. Emotion. 2013; 13:359. [PubMed: 23527510]

Hall EE, Ekkekakis P, Petruzzello SJ. The affective beneficence of vigorous exercise revisited. British Journal of Health Psychology. 2002; 7:47-66. [PubMed: 14596717] 
Hughes JR, Keely J, Naud S. Shape of the relapse curve and long-term abstinence among untreated smokers. Addiction. 2004; 99:29-38. [PubMed: 14678060]

Jha P. Avoidable global cancer deaths and total deaths from smoking. Nature Reviews Cancer. 2009; 9(9):655-664. [PubMed: 19693096]

Jha P, Peto R. Global effects of smoking, of quitting, and of taxing tobacco. New England Journal of Medicine. 2014; 370(1):60-68. [PubMed: 24382066]

John OP. The "Big Five" factor taxonomy: Dimensions of personality in the natural language and in questionnaires. In: Pervin LA, editorHandbook of Personality Theory and Research. New York: Guilford; 1990. 66-100.

Kassel JD, Shiffman S, Gnys MA, Paty J, Zettler-Segal M. Psychosocial and personality differences in chippers and regular smokers. Addictive Behaviors. 1994; 19:565-575. [PubMed: 7832015]

Kassel JD, Stroud LR, Paronis CA. Smoking, stress, and negative affect: correlation, causation, and context across stages of smoking. Psychological Bulletin. 2003; 129:270. [PubMed: 12696841]

Kopetz C, Orehek E. When the End Justifies the Means Self-Defeating Behaviors as "Rational" and "Successful" Self-Regulation. Current Directions in Psychological Science. 2015; 24:386-391.

Kruglanski AW, Orehek E. Toward a relativity theory of rationality. Social Cognition. 2009; 27:639_ 660.

Kruglanski AW, Shah J, Fishbach A, Friedman R, Chun W, Sleeth-Keppler D. Advances in Experimental Social Psychology. Vol. 34. San Diego, CA: Academic Press; 2002. A theory of goal systems; 331-378.

Levy D, Fergus C, Rudov L, McCormick-Ricket I, Carton T. Tobacco Policies in Louisiana: Recommendations for Future Tobacco Control Investment from SimSmoke, a Policy Simulation Model. Prevention Science. 2016; 17:199-207. [PubMed: 26314867]

Lewit EM, Coate D, Grossman M. The effects of government regulation on teenage smoking. Journal of Law and Economics. 1981; 24:545-569.

Ling PM, Glantz SA. Using tobacco-industry marketing research to design more effective tobaccocontrol campaigns. JAMA. 2002; 287:2983-2989. [PubMed: 12052128]

Loewenstein G. A visceral account of addiction. In: Elster J, Skog OJ, editorsGetting hooked: Rationality and addiction. New York: Cambridge University Press; 1999. 235-264.

Meijer E, Gebhardt WA, Dijkstra A, Willemsen MC, Van Laar C. Quitting smoking: The importance of non-smoker identity in predicting smoking behaviour and responses to a smoking ban. Psychology \& Health. 2015

Niaura R, Shadel WG, Britt DM, Abrams DB. Response to social stress, urge to smoke, and smoking cessation. Addictive Behaviors. 2002; 27:241-250. [PubMed: 11817765]

Ohsfeldt RL, Boyle RG, Capilouto EI. Tobacco taxes, smoking restrictions, and tobacco use. In: Chaloupka FJ, Grossman M, Bickel WK. , et al., editorsThe economic analysis of substance use and abuse: An integration of econometric and behavioral economic research. Chicago: University of Chicago Press for the National Bureau of Economic Research; 1999.

Papies EK, Barsalou LW. Grounding desire and motivated behavior: a theoretical framework and empirical evidence. In: Hofmann W, Nordgren LF, editorsThe Psychology of Desire. The Guilford Press; New York: 2015.

Persoskie A, Ferrer RA, Taber JM, Klein WMP, Parascandola M, Harris PR. Smoke-free air laws and quit attempts: Evidence for a moderating role of spontaneous self-affirmation. Social Science \& Medicine. 2015; 141:46-55. [PubMed: 26246033]

Persoskie A, Nelson WL. Just blowing smoke? Social desirability and reporting of intentions to quit smoking. Nicotine \& Tobacco Research. 2013; 15:2088-2093. [PubMed: 23884318]

Peterson DE, Zeger SL, Remington PL, Anderson HA. The effect of state cigarette tax increases on cigarette sales, 1955 to 1988. American Journal Pub Health. 1992; 82:94-96.

Ranson MK, Jha P, Chaloupka FJ, Nguyen SN. Global and regional estimates of the effectiveness and cost-effectiveness of price increases and other tobacco control policies. Nicotine \& Tobacco Research. 2002; 4:311-319. [PubMed: 12215240]

Raupach T, Brown J, Herbec A, Brose L, West R. A systematic review of studies assessing the association between adherence to smoking cessation medication and treatment success. Addiction. 2014; 109:35-43. [PubMed: 23919621] 
Rennen E, Nagelhout GE, van den Putte B, Janssen E, Mons U, Guignard R, ... Willemsen MC. Associations between tobacco control policy awareness, social acceptability of smoking and smoking cessation. Findings from the International Tobacco Control (ITC) Europe Surveys. Health Education Research. 2014; 29:72-82. [PubMed: 23861478]

Rothman AJ, Gollwitzer PM, Grant AM, Neal DT, Sheeran P, Wood W. Hale and Hearty Policies How Psychological Science Can Create and Maintain Healthy Habits. Perspectives on Psychological Science. 2015; 10:701-705. [PubMed: 26581721]

Saladin ME, Gray KM, Carpenter MJ, LaRowe SD, DeSantis SM, Upadhyaya HP. Gender differences in craving and cue reactivity to smoking and negative affect/stress cues. The American Journal on Addictions. 2012; 21:210-220. [PubMed: 22494223]

Shiffman S, Gnys M, Richards TJ, Paty JA, Hickcox M, Kassel JD. Temptations to smoke after quitting: a comparison of lapsers and maintainers. Health Psychology. 1996; 15:455. [PubMed: 8973926]

Shiffman S. Assessing smoking patterns and motives. Journal Consulting and Clinical Psychology. 1993; 61:732. [PubMed: 8245271]

Scheier MF, Carver CS, Bridges MW. Distinguishing optimism from neuroticism (and trait anxiety, self-mastery, and self-esteem): a reevaluation of the Life Orientation Test. Journal Personality and Social Psychology. 1994; 67:1063.

Tauras JA. Public policy and smoking cessation among young adults in the United States. Health Policy. 2004; 68:321-332. 321e32. [PubMed: 15113643]

Tauras JA, Johnson LD, O’Malley PM. Effects of Price and Access Laws on Teenage Smoking Initiation: A National Longitudinal Analysis. Cambridge MA: National Bureau of Economic Research; 2001. Working Paper Number 8331

Tamir M. What do people want to feel and why? Pleasure and utility in emotion regulation. Current Directions in Psychological Science. 2009; 18:101-105.

Task Force on Community Preventive Services. Recommendations regarding interventions to reduce tobacco use and exposure to environmental tobacco smoke. American Journal of Preventive Medicine. 2001; 20:10-15.

Townsend J, Roderick P, Cooper J. Cigarette smoking by socioeconomic group, sex, and age: effects of price, income and health publicity. BMJ. 1994; 309:923-926. [PubMed: 7950662]

Whittaker R, McRobbie H, Bullen C, Borland R, Rodgers A, Gu Y. Mobile phone-based interventions for smoking cessation. The Cochrane Library. 2012

Wrosch C, Heckhausen J, Lachman ME. Primary and secondary control strategies for managing health and financial stress across adulthood. Psychology and Aging. 2000; 15:1-13.

Wrosch C, Scheier MF, Carver CS, Schulz R. The importance of goal disengagement in adaptive selfregulation: When giving up is beneficial. Self and Identity. 2003a; $2: 1-20$.

Wrosch C, Scheier MF, Miller GE, Schulz R, Carver CS. Adaptive self-regulation of unattainable goals: Goal disengagement, goal re-engagement, and subjective well-being. Personality and Social Psychology Bulletin. 2003b; 29:1494-1508. [PubMed: 15018681]

Wrosch C, Scheier MF, Miller GE. Goal adjustment capacities, subjective well-being, and physical health. Social and Personality Psychology Compass. 2013; 7:847-860. Advance online publication. org/10.1111/spc3.12074. [PubMed: 25177358] 
- $\quad$ Cigarette taxation effectiveness may differ based on psychological characteristics

- Disengaging from goal pursuit under stress may be one such characteristic

- In ever-smokers low in disengagement, the tax-cessation association was positive

- In ever-smokers high in disengagement, taxation is unassociated with smoking status

- $\quad$ Our data suggest that economics-based strategies may be moderated by disengagement 


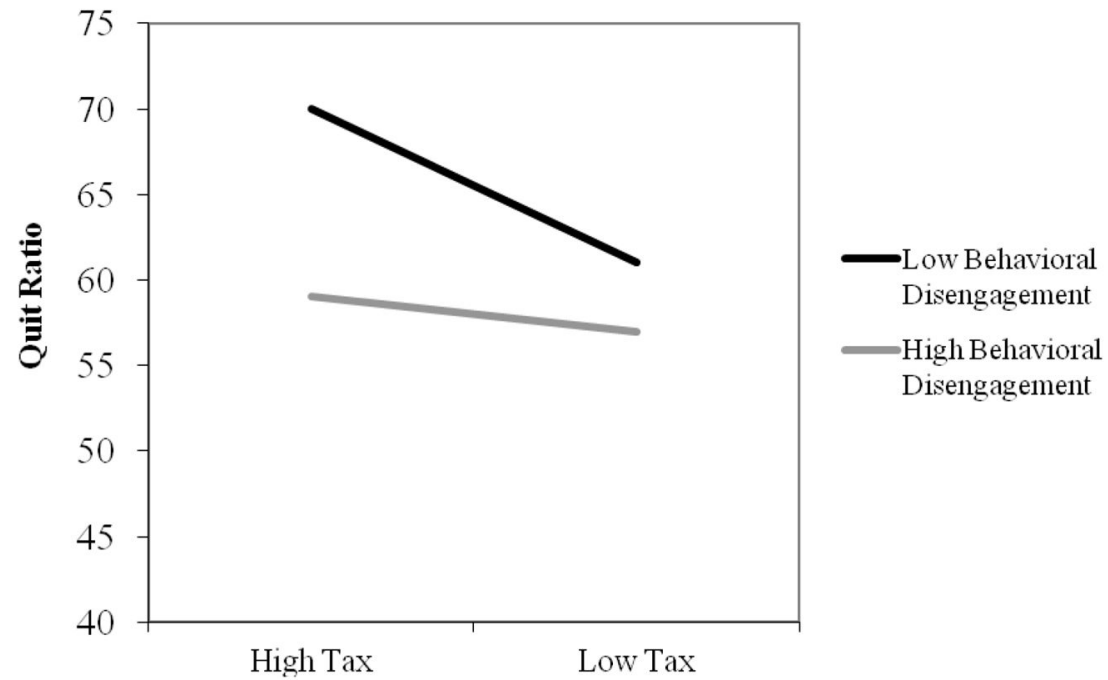

Figure 1.

Quit ratio one SD above and below the mean for cigarette tax rate and behavioral disengagement $(n=725)$. 


\section{Table 1}

Descriptive Statistics by Time

\begin{tabular}{|c|c|c|c|c|}
\hline & \multicolumn{2}{|c|}{$\begin{array}{c}\text { MIDUS 2 } \\
n=725\end{array}$} & \multicolumn{2}{|c|}{$\begin{array}{c}\text { MIDUS } 3 \\
n=336\end{array}$} \\
\hline & $M$ & $S D$ & $M$ & $S D$ \\
\hline Age & 53.19 & 10.88 & 61.22 & 9.53 \\
\hline Behavioral Disengagement & 1.77 & 0.59 & 1.79 & 0.58 \\
\hline Baseline tax rate & $\$ 0.35$ & $\$ 0.17$ & $\$ 0.73$ & $\$ 0.49$ \\
\hline Tax rate & $\$ 0.76$ & $\$ 0.49$ & $\$ 1.47$ & $\$ 0.98$ \\
\hline Self-reported health & 3.22 & 1.01 & 3.01 & 1.06 \\
\hline \multirow[t]{2}{*}{ Number of years since quit (former smokers only) } & 5.14 & 4.63 & 5.67 & 5.87 \\
\hline & $N$ & $\%$ & $N$ & $\%$ \\
\hline Female & 405 & $55.86 \%$ & 196 & $58.33 \%$ \\
\hline \multicolumn{5}{|l|}{ Race } \\
\hline White & 676 & $93.24 \%$ & 314 & $93.45 \%$ \\
\hline Black & 27 & $3.72 \%$ & 9 & $2.68 \%$ \\
\hline Other & 22 & $3.03 \%$ & 13 & $3.87 \%$ \\
\hline \multicolumn{5}{|l|}{ Education } \\
\hline Less than high school & 74 & $10.21 \%$ & 26 & $7.74 \%$ \\
\hline High school or some college & 497 & $68.55 \%$ & 234 & $69.64 \%$ \\
\hline College & 154 & $21.24 \%$ & 76 & $22.62 \%$ \\
\hline \multicolumn{5}{|l|}{ Smoking status } \\
\hline Current smoker & 243 & 33.52 & 192 & 57.14 \\
\hline Former smoker & 482 & 66.48 & 144 & 42.86 \\
\hline
\end{tabular}

J Econ Psychol. Author manuscript; available in PMC 2019 June 01. 


\section{Table 2}

Multilevel Model of Smoking Quit Ratio $(n=725)$

\begin{tabular}{|c|c|c|c|}
\hline & OR & $95 \% \mathrm{CI}$ & p \\
\hline Age & 1.01 & $1.00,1.03$ & .024 \\
\hline Female & 0.79 & $0.61,1.02$ & .069 \\
\hline \multicolumn{4}{|l|}{ Race } \\
\hline White & ref & ref & ref \\
\hline Black & 0.82 & $0.40,1.69$ & .598 \\
\hline Other & 0.30 & $0.10,0.95$ & .031 \\
\hline \multicolumn{4}{|l|}{ Education } \\
\hline Less than high school & ref & ref & ref \\
\hline High school or some college & 0.55 & $0.33,0.92$ & .002 \\
\hline College & 1.33 & $0.97,1.82$ & .023 \\
\hline Self-reported health & 1.01 & $0.86,1.15$ & .890 \\
\hline Tax rate $\mathrm{T} 1$ & 1.05 & $0.86,1.28$ & .635 \\
\hline Tax rate $\mathrm{T} 2$ & 1.10 & $0.97,1.26$ & .142 \\
\hline Behavioral disengagement & 0.94 & $0.88,1.01$ & .094 \\
\hline Tax rate $\mathrm{T} 2 \mathrm{X}$ Behavioral disengagement & 0.95 & $0.90,0.99$ & .026 \\
\hline
\end{tabular}

Generalized $\chi^{2}=1027.30, \chi^{2} / d$ fratio $=0.97$ 